\title{
rempons
}

EGSM:

\section{Guerras del sexo: el debate entre feministas radicales y libertarias'}

\author{
Ann Ferguson
}

En los últimos cuatro años hubo una creciente polarización de las feministas estadounidenses en dos bandos, en relación a la moral sexual feminista. En el primer bando, las feministas radicales, sostienen que la sexualidad en una sociedad patriarcal, implica peligro - esto es, que las prácticas sexuales perpetuán la violencia contra las mujeres. En el bando opuesto, las autodenominadas "antimoralistas", a quienes yo llamo "feministas libertarias", sostienen que la característica clave de la sexualidad es el aspecto potencialmente liberador del intercambio de placer entre personas con capacidad de consentimiento. Tal como están constituidas, estas no son posiciones excluyentes: es coherente sostener que las prácticas sexuales contemporáneas involucran tanto placer como peligro".

¿Qué explica entonces la actual dicotomía, la amarga oposición, entre feministas radicales y libertarias en relación a la moral sexual? Sostengo que

\footnotetext{
I "Guerras del sexo" es la expresión comúnmente utilizada para nombrar los debates del feminismo norteamericano en torno a la sexualidad durante la segunda ola. Decidimos conservar esta enunciación para ser más fieles con el texto original de la autora y con el contexto feminista en el cual se produjeron estos debates. Sin embargo, en consonancia con la opinión de la autora del artículo y con las teorías feministas contemporáneas que distinguen entre sexo, sexualidad y género, sería más adecuada la expresión "guerras de la sexualidad" (N. del. T.).

*Título original: "Sex War: The Debate between Radical and Libertarian Feminists". En Journal of Women in Culture and Society 1984, vol. 10, no. 1. Traducción de Felipe Gonzalez y Trinidad Traverso. Revisión técnica: Cecilia Varela.

"Es importante recordar que las feministas, en la primera fase del movimiento de mujeres, a finales de la década de 1960, no realizaban esta distinción al pensar la sexualidad; enfatizaban tanto la defensa del derecho de las mujeres al placer (orgasmo femenino) como a la protección legal contra los peligros de las relaciones sexuales heterosexuales: embarazos no deseados (por ejemplo, el derecho al aborto). Durante la segunda fase, a comienzos de los años 70, las feministas se centraron más en el derecho de las mujeres al placer sexual con otras mujeres (feminismo lésbico). Sólo en la tercera fase del movimiento, cuando el placer sexual como meta ya había sido culturalmente legitimado, muchas feministas comenzaron a enfatizar la violencia y el peligro de instituciones heterosexuales como la pornografía.
}

Revista Zona Franca- Centro de estudios interdisciplinario sobre las mujeres (CEIM)- Maestría poder y sociedad desde la problemática de género (MG), Rosario, Argentina. ISSN, 2545-6504 http://zonafranca.unr.edu.ar/index.php/ZonaFrancal Numero 27 (2019). 
existen diferencias filosóficas e históricas entre estos dos bandos. Históricamente, las feministas radicales han sido parte o se han identificado con la comunidad lesbofeminista que rechaza el sexo heterosexual dominado por los varones. Las feministas radicales tienden a condenar el sadomasoquismo, la pornografía, la prostitución, el sexo casual, las relaciones intergeneracionales y los juegos de roles sexuales. Rechazan dichas prácticas debido a análisis implícitos y explícitos que asocian los roles sexuales de dominación y subordinación a la perpetuación de la dominación masculinal'I. Por otro lado, las feministas libertarias generalmente son heterosexuales o lesbianas que están a favor de cualquier tipo de actividad sexual consensuada que brinde placer a los participantes, incluyendo sadomasoquismo, pornografía, sexo casual, relaciones intergeneracionales y juegos de roles sexuales. Recientemente estos temas llegaron a su punto más álgido en relación a desacuerdos en torno a la condena que las feministas radicales realizan a la pornografía y el sadomasoquismo, particularmente por grupos como Mujeres contra la Pornografía (WAP por sus siglas en inglés) y Mujeres Contra la Violencia Hacia las Mujeres (Women Against Violence Against Women).Algunas de las representantes del feminismo libertario, que se identifican como feministas y lesbianas "S/M" (sadomasoquistas), argumentan que el moralismo de las feministas radicales estigmatiza a minorías sexuales como a las parejas lesbianas butch/femme, sadomasoquistas, parejas de hombres mayores con chicos jóvenes, etc., legitimando el sexo convencional y al mismo tiempo, propiciando un retorno a una visión estrecha, conservadora y "femenina" de la sexualidad ideal ${ }^{\mathrm{l}}$.

III Ver Robin Linden, Darlene Pagano, Diana Russell, y Susan Leigh Star, eds., Against SadoMasochism (East Palo Alto, Calif.: Frog in the Well Press, 1982); Susan Brownmiller,Against Our Will: Men, Women and Rape (New York: Simon \& Schuster, 1976); Kathleen Barry, Female Sexual Slavery (Englewood Cliffs, NJ.: Prentice-Hall, Inc., 1979); Andrea Dworkin, Pornography: Men Possessing Women (New York: G. P. Putnam's Sons, 1981); Susan Griffin, Pornography and Silence: Culture's Revolt against Nature (New York: Harper \& Row,1982); Laura Lederer, ed., Take Back the Night: Women on Pornography (New York: Dell Publishing Co., 1981); y Nancy Myron y Charlotte Bunch, eds., Lesbianism and the Women's Movement (Baltimore: Diana Press, 1975)

IV Ver Pat Califia, "Feminism and Sadomasochism," Heresies 12 3, no. 4 (1981): 30-34;Gayle Rubin, "The Leather Menace: Comments on Politics and S/M," en Coming to Power:Writings and Graphics on Lesbian SIM, ed. SAMOIS (Boston: Alyson Publications, 1982); Gayle Rubin, Deirdre

Revista Zona Franca- Centro de estudios interdisciplinario sobre las mujeres (CEIM)- Maestría poder y sociedad desde la problemática de género (MG), Rosario, Argentina. ISSN, 2545-6504 http://zonafranca.unr.edu.ar/index.php/ZonaFranca| Numero 27 (2019). 
Un problema en relación al actual debate entre feministas radicales y libertarias es que estas posturas opuestas no exploran todas las posibles perspectivas feministas en relación al placer sexual, la libertad sexual y el peligro. Ambas posturas se basan en una serie de postulados filosóficos implícitos acerca de la naturaleza de la sexualidad, el poder y la libertad, que nunca han sido apropiadamente desarrollados ni defendidos. Consecuentemente, cada lado acusa al contrario de ignorar importantes aspectos de la sexualidad y de la libertad sexual. Pero ambas posturas pueden ser discutidas desde una tercera posición que yo llamo una (y no la) perspectiva socialista feminista. Aunque no cuento con espacio suficiente para desarrollar esa perspectiva adecuadamente, espero poder aportar al debate entre estas dos posiciones teóricas del movimiento de mujeres sobre la moral sexual, describiendo y criticando sus paradigmas subyacentes en torno a la sexualidad, el poder social y la libertad sexual.

\section{Dos Paradigmas Contrastados}

La visión del feminismo radical sobre la sexualidad incluye los siguientes postulados:

1. Las relaciones sexuales heterosexuales generalmente están caracterizadas por una ideología de la cosificación sexual (donde los hombres son los sujetos/amos y las mujeres son los objetos/esclavas) que sustenta la violencia sexual contra las mujeres.

2. Las feministas deberían repudiar cualquier práctica sexual que sustente o "normalice" la violencia sexual masculina.

English, y Amber Hollibaugh, "Talking Sex: A Conversation on Sexualityand Feminism," Socialist Review 58 11, no. 4 (July/August 1981): 43-62; and Gayle Rubin,"Sexual Politics, the New Right and the Sexual Fringe," en The Age Taboo: Gay Male Sexuality,Power and Consent, ed. Daniel Tsang (Boston: Alyson Publications, 1981).

Revista Zona Franca- Centro de estudios interdisciplinario sobre las mujeres (CEIM)- Maestría poder y sociedad desde la problemática de género (MG), Rosario, Argentina. ISSN, 2545-6504 http://zonafranca.unr.edu.ar/index.php/ZonaFrancal Numero 27 (2019). 
3. Como feministas debemos reclamar el control sobre la sexualidad femenina preocupándonos por nuestras propias prioridades en relación a la sexualidad, las cuales difieren de las de los varones -esto es, una sexualidad más centrada en la intimidad y menos en el desempeño.

4. La relación sexual ideal debe darse entre dos personas emocionalmente involucradas, en pie de igualdad, con plena capacidad de consentimiento y que no participan de roles polarizados.

De estos cuatro aspectos de la ideología sexual del feminismo radical, es posible abstraer los siguientes presupuestos teóricos acerca de la sexualidad, el poder social y la libertad sexual:

5. La sexualidad humana es una forma de expresión entre las personas que crea lazos y comunica emociones (teoría de la primacía de la intimidad).

6. Teoría del poder social: en las sociedades patriarcales, la sexualidad se convierte en una herramienta de dominación masculina a través de la cosificación sexual. Este es un mecanismo social que opera a través de la institucionalización de los roles masculinos y femeninos en la familia nuclear patriarcal. La consecuente ideología de la cosificación sexual es el sadomasoquismo, que implica la masculinidad como control sádico sobre las mujeres y la feminidad como sumisión a la voluntad masculina.

7. La libertad sexual requiere la igualdad sexual de las personas involucradas y su respeto mutuo, como sujetos y como cuerpos. También requiere la eliminación de todas las instituciones patriarcales (por ejemplo, la industria pornográfica, la familia patriarcal, la prostitución y la heterosexualidad obligatoria) y las prácticas sexuales patriarcales (sadomasoquismo, sexo casual, sexo intergeneracional, relaciones de lesbianas butch/femme) ya que en ellas se produce la cosificación. 
El paradigma de las feministas libertarias puede ser resumido de manera que muestre el claro contraste que tiene con el paradigma del feminismo radical:

1. La heterosexualidad, al igual que otras prácticas sexuales, está caracterizada por la opresión. Las normas de la sexualidad patriarcal y burguesa reprimen los deseos y placeres sexuales de toda la sociedad por medio de la estigmatización de las minorías sexuales para así mantener a la mayoría "pura" y bajo control.

2. El feminismo debería repudiar cualquier análisis teórico, restricciones legales o juicios morales que estigmaticen a las minorías sexuales y por ello restrinja la libertad de todos.

3. Como feministas deberíamos reclamar el control sobre la sexualidad femenina demandando el derecho a cualquier práctica sexual que nos brinde placer y satisfacción.

4. La relación sexual ideal debe darse entre iguales con plena capacidad de consentir, que negocian para maximizar el placer mutuo y la satisfacción sexual de cualquier manera que elijan.

Los paradigmas generales sobre la sexualidad, el poder social y la libertad sexual que se pueden inferir de esta ideología sexual son:

5. La sexualidad humana es un intercambio de placeres físicos, sexuales, eróticos y genitales (teoría de la primacía del placer).

6. Teoría del poder social: las instituciones sociales, relaciones y discursos que distinguen lo normal/legítimo/saludable de lo anormal/ilegítimo/enfermo y privilegian ciertas expresiones sexuales sobre otras, institucionalizan la represión sexual y crean una jerarquía de poder social e identidades sexuales.

7. La libertad sexual requiere prácticas oposicionales, esto es, prácticas que transgredan las categorías socialmente respetables de la sexualidad y se opongan

Revista Zona Franca- Centro de estudios interdisciplinario sobre las mujeres (CEIM)- Maestría poder y sociedad desde la problemática de género (MG), Rosario, Argentina. ISSN, 2545-6504 http://zonafranca.unr.edu.ar/index.php/ZonaFranca| Numero 27 (2019). 
a trazar una frontera que delimite lo políticamente correcto en el terreno de la sexualidad.

\section{Críticas al feminismo radical y al feminismo libertario}

Las feministas radicales afirman el valor de la intimidad emocional en las relaciones sexuales mientras que las feministas libertarias enfatizan la obtención de placer. Pero ni las emociones ni el placer físico pueden aislarse y discutirse en el vacío. Estos valores solo pueden ser juzgados en un contexto histórico específico ya que no hay una función universal que puede asignarse la sexualidad. Los placeres corporales, la intimidad emocional, la reproducción, tienen distintas prioridades para diferentes culturas, clases, razas en diferentes momentos de la historia.

Es por eso que debemos rechazar, tanto la visión del feminismo radical que sostiene que el patriarcado ha robado la sexualidad femenina, esencialmente emocional, como la visión del feminismo libertario que argumenta que la represión sexual ha negado a las mujeres el placer erótico. Ambas posturas son esencialistas. Es cierto que en las sociedades patriarcales y occidentales contemporáneas se espera que la sexualidad de las "mujeres respetables" esté vinculada a la búsqueda de intimidad emocional, en oposición a la sexualidad masculina, asociada a la búsqueda de placer físico. Pero, no en todas las sociedades, ni siquiera en todas las clases sociales y razas de las sociedades occidentales, la sexualidad ha estado organizada en un sistema tan dicotómico. Ambos bandos están pensando las identidades de género -que son desarrollos históricos- como características universales de la humanidad.

El problema tanto con la teoría radical como con la libertaria es que ambas describen el poder social de una manera demasiado simple. Quizás no exista una estrategia universal para recuperar el poder sexual. Aunque las feministas radicales están en lo correcto cuando señalan que la cosificación sexual define a

Revista Zona Franca- Centro de estudios interdisciplinario sobre las mujeres (CEIM)- Maestría poder y sociedad desde la problemática de género (MG), Rosario, Argentina. ISSN, 2545-6504 http://zonafranca.unr.edu.ar/index.php/ZonaFranca| Numero 27 (2019). 
la heterosexualidad como construcción patriarcal, exageran en su descripción. Necesitamos un estudio más detallado de las fantasías sexuales y sus efectos. Incluso las fantasías que involucran imágenes de dominación y sumisión pueden estimular a algunas mujeres y llevarlas a disfrutar más plenamente del sexo, un fenómeno que, al mejorar la conexión con sus propios cuerpos, puede ayudarlas a empoderarse. Sin embargo, para crear prácticas sexuales alternativas que también generen empoderamiento es necesario una terapia sexual feminista que ayude a las mujeres y a los hombres, a crear fantasías sexuales que no involucren esas imágenes de dominación y sumisión.

Las feministas libertarias son ingenuas al insistir que cualquier tipo de actividad sexual consensuada debe ser aceptable para el feminismo, ya que es necesario examinar el concepto de consentimiento en sí mismo para explorar las estructuras de poder ocultas que sitúan a las mujeres en posiciones de desigualdad, y por ello, coercitivas. Que algunas feministas piensen que consienten a prácticas sadomasoquistas y al consumo de pornografía, no implica que estén dadas las condiciones para un consentimiento verdadero. Las feministas libertarias deben demostrar que en estas situaciones su capacidad de consentimiento difiere del de las esposas golpeadas que no quieren abandonar a sus parejas violentas, cosa que aún no han logrado argumentar convincentemente.

La pornografía es un tema especialmente difícil, en parte porque la distinción entre producciones eróticas y pornográficas depende del contexto, o sea, del género, clase y cultura de la audiencia. Las prácticas, discursos e imágenes pornográficas principalmente dirigidas a hombres, reducen a las mujeres a objetos sexuales. Pero hay otros discursos populares dirigidos a mujeres o a públicos mixtos, que contradicen esto, por ejemplo la literatura erótica, las películas eróticas y las telenovelas. 
Si miramos al sistema total de esos discursos (tanto pornográficos como eróticos), encontraremos un conjunto de presupuestos que entran en conflicto. Estos presupuestos constituyen una mezcla distintiva de ideales patriarcales y de individualismo liberal, característicos de las sociedades capitalistas patriarcales más desarrolladas. Por un lado, la ideología del amor romántico permea muchas de las producciones eróticas, generando una idea de que los vínculos sexuales deben darse entre parejas donde ambos tienen derecho al placer sexual por igual. Por otro lado, es también cierto que en muchos de los materiales sexualmente explícitos el mensaje que se trasmite es lo que Andrea Dworkin y Kathleen Barry llaman "sadismo cultural": la idea de que el hombre debe iniciar y controlar el acto sexual y que la mujer debe someterse a esto (los hombres son consumidores de sexo y las mujeres proveedoras).

Tanto las libertarias como las radicales eligen enfatizar en lados opuestos de estas contradicciones. En cambio, argumento que debemos desarrollar una erótica y una educación sexual feministas que ayuden a las personas con el objetivo de hacerlas conscientes de estas contradicciones y que esto las ayude a desarrollar nuevas formas de producir fantasías eróticas feministas. Esta erótica y educación deben darse en diversos contextos (escuelas, telenovelas, novelas rosas, al igual que en el arte de vanguardia) y estar dirigidas a todo tipo de audiencias. Esto implica, evitar el "vanguardismo sexual" tanto de las radicales como de las libertarias, quienes se vinculan únicamente con comunidades contraculturales cerradas (lesbianas, feministas radicales de clase media y otras minorías sexuales) $)^{\mathrm{v}}$.

Para avanzar en la resolución de este dilema, creo que debemos adoptar de forma transitoria una ética sexual feminista que distinga entre prácticas sexuales

\footnotetext{
$\checkmark$ La crítica a las vanguardias políticas no implica que las contraculturas son irrelevantes en una estrategia feminista para el cambio social. Al contrario, las redes entre feministas y grupos de la diversidad sociosexual son necesarias tanto para la supervivencia de ambos como para desafiar las normas sociales y sexuales. El punto es que el cambio social dentro de las prácticas culturales dominantes no se puede lograr sólo mediante políticas sexuales vanguardistas dentro de subculturas aisladas.
}

Revista Zona Franca- Centro de estudios interdisciplinario sobre las mujeres (CEIM)- Maestría poder y sociedad desde la problemática de género (MG), Rosario, Argentina. ISSN, 2545-6504 http://zonafranca.unr.edu.ar/index.php/ZonaFrancal Numero 27 (2019). 
básicas, riesgosas y prohibidas. Las prácticas sexuales prohibidas son aquellas en las que las relaciones de dominación y sumisión son tan explícitas que las feministas sostienen que deberían ser ilegales. Esas prácticas incluyen: ataques incestuosos, violación, violencia ${ }^{\mathrm{Vl}}$ doméstica y relaciones sexuales entre niños pequeños y adultos. La diferencia entre una práctica prohibida y una práctica riesgosa es epistemológica: esto es, que una práctica es considerada "riesgosa" si se sospecha que conduce a relaciones de dominación/sumisión aunque no existan pruebas concluyentes de esto. Mientras que las prácticas prohibidas son aquellas en las que sí existe tal evidencia. El sadomasoquismo, la pornografía mainstream, la prostitución y los vínculos del varón-proveedor y la mujer-ama de casa dentro de la familia nuclear, son todas prácticas riesgosas desde un punto de vista feminista. Esto no quiere decir que las feministas no tengan derecho a realizar estas prácticas, pero como hay evidencia contradictoria en relación al rol que cumplen estas prácticas en las estructuras de dominación patriarcal, no pueden incluirse en la lista de prácticas básicas feministas. Las prácticas básicas feministas pueden incluir tanto el sexo casual como vínculos sexoafectivos más comprometidos, la crianza compartida y las relaciones comunitarias. Estas prácticas se distinguen por la negociación consciente y la ecualización de las partes en términos de las diferentes relaciones de poder -económicas, sociales (por ejemplo edad, género, etc.)-que se dan entre ellas. Una ética feminista debe ser pluralista respecto a las prácticas básicas y riesgosas. Esto quiere decir que las feministas deben poder elegir entre prácticas básicas y riesgosas sin miedo a la condena moral por parte de otras feministas.

\section{Conclusiones}

VI Desarrollo estas distinciones de manera más profunda en Ann Ferguson, "The Sex Debate within the Women's Movement: A Socialist-Feminist View," Against the Current (September/ October 1983), pp. 10-16.

Revista Zona Franca- Centro de estudios interdisciplinario sobre las mujeres (CEIM)- Maestría poder y sociedad desde la problemática de género (MG), Rosario, Argentina. ISSN, 2545-6504 http://zonafranca.unr.edu.ar/index.php/ZonaFranca| Numero 27 (2019). 
Nuestras prácticas sexuales contemporáneas están caracterizadas tanto por relaciones de poder que implican dominación y sumisión, como por un potencial liberador. Para evitar las simplificaciones tanto de las posiciones radicales como de las libertarias en relación a la sexualidad, necesitamos un paradigma que pueda ser historizado. Es por esto que sugiero el uso de "modos de producción sexual/afectiva"VII. Concebir el patriarcado contemporáneo como un sistema en desarrollo permite explorar las contradicciones en nuestras identidades sexuales,

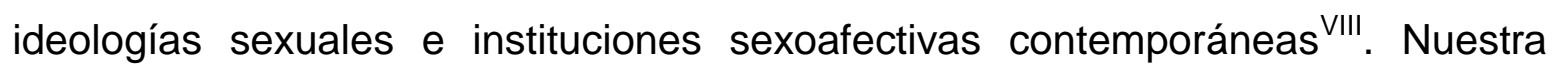
visión de una sociedad sexualmente liberada debería situar a las prácticas sexuales genitales dentro de un complejo más amplio de relaciones sexoafectivas. Las relaciones de parentesco y de amistad están todas implicadas en una ecualización sexual, como también lo están las dinámicas de poder raciales y de clases $^{\mathrm{IX}}$. Una ética sexual feminista completamente elaborada debe explorar estas relaciones con mucho más detenimiento de lo que hemos hecho hasta la fecha.

VII Este concepto está vinculado a lo que Gayle Rubin denomina "sistema sexo/género" ("The Traffic in Women: Notes toward a 'Political Economy' of Sex," en Toward an Anthropology of Women, ed. Rayna Rapp Reiter [New York: Monthly Review Press, 1975]). Desarrolló el concepto para incluir la producción, y los intercambios sexuales, de cuidados y afectos en "Women as a New Revolutionary Class in the U.S.A.," en Between Labor and Capital, ed. Pat Walker (Boston: South End Press, 1979).

VIII Ver Ann Ferguson y Nancy Folbre, "The Unhappy Marriage of Capitalism and Patriarchy," en Women and Revolution: A Discussion of the Unhappy Marriage of Marxism and Feminism, ed. Lydia Sargent (Boston: South End Press, 1981); y Ann Ferguson, "Patriarchy, Sexual Identity, and the Sexual Revolution," en Ann Ferguson, Jacquelyn N. Zita, y Kathryn Pyne Addelson, "Viewpoint: On 'Compulsory Heterosexuality and Lesbian Existence': Defining the Issues", Signs: Journal of Women in Culture and Society 7, no. 1 (Autumn 1981): 158-72.

${ }^{\mathrm{IX}}$ Ann Ferguson, "On Conceiving Motherhood and Sexuality: A Feminist Materialist Perspective," en Mothering: Essays in Feminist Theory, ed. Joyce Trebilcot (Totowa, N.J.: Rowman \& Allenheld, 1984).

Revista Zona Franca- Centro de estudios interdisciplinario sobre las mujeres (CEIM)- Maestría poder y sociedad desde la problemática de género (MG), Rosario, Argentina. ISSN, 2545-6504 http://zonafranca.unr.edu.ar/index.php/ZonaFranca| Numero 27 (2019). 